\title{
Tourist development and host-guest interaction: An economic exchange theory
}

This is the peer reviewed version of the following article:

Original:

Bimonte, S., Punzo, L.F. (2016). Tourist development and host-guest interaction: An economic exchange theory. ANNALS OF TOURISM RESEARCH, 58, 128-139 [10.1016/j.annals.2016.03.004].

Availability:

This version is availablehttp://hdl.handle.net/11365/1000539

since 2016-11-23T16:21:07Z

\section{Published:}

DOI:10.1016/j.annals.2016.03.004

Terms of use:

Open Access

The terms and conditions for the reuse of this version of the manuscript are specified in the publishing policy. Works made available under a Creative Commons license can be used according to the terms and conditions of said license.

For all terms of use and more information see the publisher's website.

(Article begins on next page) 


\title{
Tourist development and host-guest interaction
}

\section{An economic exchange theory}

Salvatore Bimonte and Lionello F. Punzo

University of Siena

\author{
A revised version of this paper has been published on \\ Annals of Tourism Research 2016 \\ http://authors.elsevier.com/a/1SoVOaZ3EFh1d
}

\begin{abstract}
Theoretical research on the impacts of tourism has a discernible bias towards residents' perceptions. To understand the evolution and dynamics of tourism, residents' perceptions have to be analysed as part of an exchange process involving both residents and tourists. A conceptual framework of hostguest relations is required. This paper presents an economic model that builds on evidence that tourism involves the meeting of two populations. Their interactions and experiences influence their attitudes and opinions. This causes structural changes in individual preferences that affect residents' perceptions of tourism and tourists' willingness to pay. To interpret this process we use the Edgeworth Box, representing the "exchange" in terms of "resource-space" against income.
\end{abstract}

\section{Introduction}

Tourism is globally recognized as a major industry in terms of job creation, receipts (WTTC, 2014) and powerful discretionary instruments for distributing wealth and driving local development. As a free movement of people within and across national boundaries, it entails the meeting of individuals and communities, allowing people to build social relationships, experience positive emotions, and expand their knowledge. Tourism is therefore officially celebrated as an agent of economic growth and development (Sharpley, 2015). Nevertheless, its role has also been questioned. In fact, together with its alleged positive impacts, its fast growth and often uncontrolled expansion has had many social and environmental side effects. Local communities might therefore face a kind of “development dilemma" (Telfer \& Sharpley, 2008) or trade-off between perceived benefits and 
costs. A balanced and equitable distribution of costs and benefits is considered fundamental for the successful development of tourism (Andriotis \& Vaughan, 2003). Should the costs of tourism outweigh the benefits, then some or all hosts may withdraw their support for tourism (Lawson et al., 1998), an aspect not widely acknowledged in the literature (Sharpley, 2014). Without doubts, the goodwill of local residents is considered an important requirement for the success and sustainability of any tourist development.

Many studies investigate the relationships between residents' perception of the impacts of tourism and support for tourist development (among the most recent see Bimonte \& Faralla, 2016; Gursoy et al., 2010; Nunkoo \& Gursoy, 2012). The hypothesis put forward is that the success and sustainability of any tourist development crucially depend on acceptance of tourists and touristrelated plans by the local community (Bimonte, 2013; Bimonte \& Punzo, 2011; Jurowski \& Gursoy, 2004; Lepp, 2007; Pérez \& Nadal, 2005), which in turn depends on the balance of perceived costs and benefits (Andriotis \& Vaughan, 2003). This awareness, together with recognition of the growing costs associated with tourism, underlies the now considerable literature on residents' perceptions of tourism (Sharpley, 2014)

Tourism involves a meeting of two populations: a better known, stable population (residents) and a generally unknown and variable one (tourists) (Bimonte, 2008). It implies interactions and experiences that may influence guests' and/or hosts' attitudes, opinions, and ultimately lifestyles (Sharpley, 2008). The quality and nature of the interaction also affects residents' perceptions of tourism and tourists' willingness to pay (Bimonte \& Punzo, 2011). Attention therefore has to be paid to the pay-off of both residents and tourists. Only mutually beneficial development can prevent latent conflicts and the sometimes disastrous effects of competition (Bimonte, 2008; Bimonte and Punzo, 2007; Getz and Timur, 2005; Gursoy and Rutherford, 2004; Cater, 1993).

To analyse and understand this phenomenon, a conceptual framework of host-guest relations is required, but is rarely considered (Sharpley, 2014). In fact, from the outset, investigation has mainly focused on the residents' side and models have been developed to theorize the relationship between tourism, residents' perceptions of impacts and residents' responses. The most famous are the Tourist Area Life Cycle (TALC) (Butler 1980; 2006) and the Irridex model (Doxey, 1975; Fridgen, 1991). They constitute a reference framework for most studies on resident attitudes to tourism, now a major topic in the literature on tourism (McGehee \& Anderek, 2004).

However, as stated by various authors (see for example Sharpley, 2014), these studies mainly run quantitative analyses based on surveys, while there is a dearth of theoretical research capable of 
generalizing the results and explaining what residents perceive and why (Ap, 1990; Deery et al., 2012; Woosnam, 2012). Moreover, they mainly focus on one of the two "contractors", i.e. the resident, while the tourist is overlooked. Some progress has been made in a number of studies that draw on social exchange theory, but again there is a discernible bias towards residents that limits the possibility of understanding residents' perceptions as part of an exchange process (Woosnam, 2012).

Here we endeavour to develop a theoretical tourist-host economic model based on social exchange theory. We make three basic assumptions:

- tourism involves the meeting of at least two non-homogeneous populations, residents and tourists;

- both populations, presumably made up of communities, have their own needs, interests and expectations with regard to the benefits and costs of the encounter;

- the populations have to reach an agreement on how to simultaneously use and/or share local resources and how much to exploit them.

In this framework, the contractors develop an exchange process to optimize their well-being while trying to minimize the costs implied by tourism. To do so, both have to appraise and compare the costs and benefits implied by the exchange: local citizens determine their Willingness to Accept (WTA) for endorsing tourist development in their community; tourists determine their Willingness to Pay (WTP) for tourist activities. An exchange occurs when for given participants' preferences and contextual factors, a balance (equilibrium) between costs and benefits emerges for both (all) players. To represent and interpret this process we use the Edgeworth Box framework, where the "exchange" is represented in terms of "resource-space" against income. The (perceived) "disutility" and "utility" generated by the ensuing costs and benefits depend on players' preferences that in turn depend on the nature and history of the interactions that affect contextual factors.

Although it mainly draws on Social Exchange Theory (SET), widely used in the literature on residents' attitudes to tourism (Gursoy \& Rutherford, 2004), it includes and connects with other perspectives, such as carrying capacity (Bimonte \& Punzo, 2011; 2007), the "Irridex" model (Doxey, 1975) and tourist area life cycle (Butler, 1980). We believe these theories may be combined to develop a more general model without risk of simplistic syncretism. 


\section{Tourism and resident attitudes: a review of the literature}

Tourism is considered a major driver of local growth and development. It was also recently acknowledged as one of the largest self-initiated commercial enterprises for creating happiness on the planet (Pearce, 2009; Pearce et al., 2011). Its economic, social and environmental impacts have advised caution with regard to tourist development (Gursoy et al., 2002; Northcote \& Macbeth, 2006; Saarinen, 2006; Saarinen et al., 2011). They are said mainly to affect the hosts (Wall \& Mathieson, 2006) who may subsequently withdraw their support for tourism (Lawson et al., 1998). Since support of the host community is considered fundamental for tourism to thrive (Jurowski \& Gursoy, 2004), most of the literature on the subject is about residents' perceptions of the impacts of tourism.

The theoretical frameworks of reference of many of these studies are the Irridex model (Doxey, 1975; Fridgen, 1991) and the Tourist Area Life Cycle (TALC) (Butler, 2006; Butler, 1980). The former is a four-stage theoretical model (euphoria-apathy-annoyance-antagonism) that mainly focuses on host community responses to tourism. It assumes that locals are initially inclined to have a positive attitude to tourism (which is not necessarily so), but their perception of impact and their level of acceptance tend to change as tourism increases (Teye, Sonmez, \& Sirakaya, 2002), though not necessarily, it is sustained, in a deterministic and generalizable way (Gursoy, Chi, \& Dyer, 2010; King, Pizam, \& Milman, 1993). It asserts that the adverse impacts of tourism produce some degree of irritation in the host community. The irritation depends on the number of tourists and the degree of incompatibility between residents and tourists. ${ }^{1}$

Although similar in terms of expected results, TALC focuses on tourists' responses. It borrows from product cycle theory and asserts that tourist destinations follow a similar pattern, from discovery to maturity. During this process tourist facilities and infrastructure increase, so initially does the number of tourists. On approaching carrying capacity and maturity, the number of visitors starts to decline. TALC shares many limits with the Irridex model (Wall \& Mathieson, 2006) and therefore has been criticised especially for its simplistic assumptions (Mason \& Cheyne, 2000; Tosun, 2002; Dyer et al., 2007).

Other theoretical frameworks have been suggested to explain the relationship between tourists and residents: for example those proposed by Dogan (1989) and Ap \& Crompton (1993). In different ways, they both concentrate on residents' responses to tourism rather than their attitudes, the former

\footnotetext{
${ }^{1}$ On this aspect see also Bimonte \& Punzo (2007) where the interaction between tourists and residents is presented in terms of conflict and evolutionary game.
} 
highlighting that tourism may transform a relatively homogeneous community into a relatively heterogeneous one, which implies a range of responses to tourism. ${ }^{2}$

Considering the results of previous models, attention has been paid to factors that may influence residents' attitudes and responses to tourism, with the aim of providing information for planning tourism (Ap, 1992; Vargas-Sánchez et al., 2009). Hence, a rich literature flourished on the social, economic and environmental impacts of tourism, host communities' attitudes, perceptions and responses to tourism, and factors that may influence them (for a review see Harrill, 2004; Nunkoo et al., 2013; Sharpley, 2014).

Though not always convergent, the emprical results have allowed some advances in knowledge and understanding. However, the different methods, sampling technicques, frameworks and segmentations used and the variety of variables investigated make any generalization difficult (Sharpley, 2014; Williams \& Lawson, 2001). With regard to generalization, an aspect thought to account for the difficulty of developing a conceptual framework is the "atheoretical" foundation of studies (Harrill, 2004).

In order to overcome or mitigate the lack of generalizibility of results, attempts have been made to find a theoretical base for research into tourism, in particular residents' perceptions of tourism (Ap, 1992). A number of studies draw on social exchange theory, and to a lesser extent, social representations theory, even if "the contribution of these theoretical frameworks to explaining or understanding residents' perceptions remains unclear" (Sharpley, 2014, p. 45). The former theory postulates that an individual's attitudes to tourism depend on his evaluation of its perceived impacts (Andereck et al., 2005). Thus research has been aimed at elaborating a cost-benefit appraisal to determine local citizens' inclination to participate in exchange with tourists and to endorse tourist development in their own community (Ap, 1992; 1990; Ap \& Crompton 1993; Gursoy \& Kendall 2006; Jurowski, Uysal, \& Williams, 1997; Kayat, 2002). It focuses on the perceived impact of tourism, distinguishing socioeconomic, cultural and environmental impacts (Andereck and Vogt, 2000; Harrill, 2004).

Social representation theory has also been used as a theoretical basis for research into tourism. It focuses on "the content of social knowledge and the way this knowledge is created and shared by people in various groups, societies or communities" (Pearce et al., 1996). Rather than relying on individual interpretations and reactions to events, it emphasizes the social influences and interactions of the community. It is therefore considered useful for explaining social conflicts and

\footnotetext{
${ }^{2}$ For a survey and more detailed analysis see Monterrubio-Cordero (2008).
} 
individual reactions to events. In fact, social representation theory claims that "social knowledge is a combination of individual and societal values, ideas and practices that individuals use to describe and react to a stimulus" (Murphy \& Murphy, 2004, p. 46). However, although social represenatation theory offers a fertile reference framework, its usefulness and value still lack the support and recognition of empirical studies (Monterrubio-Cordero, 2008).

Other influential intergroup theories, such as Integrated Threat Theory, the Unified Instrumental Model of Group Conflict and Intergroup Emotion Theory, have been largely overlooked (Ward and Berno, 2011).

Despite indisputable attempts to give the research a theoretical basis, most studies tend to be basically exploratory and descriptive in nature (Ap, 1990; Wall \& Mathieson, 2006; for a survey see Deery et al., 2012; Nunkoo et al., 2013; Sharpley, 2014). Moreover, while awareness of the necessity to frame the analysis in a host-guest interaction framework is emerging (Ap, 1992), a discernible bias remains towards residents' and hosts' perceptions and responses.

As we have remarked, tourism involves a meeting of at least two populations, presumably divided into communities. It is essentially a social phenomenon that entails interaction between a temporary and a stable population with exchange of valuable resources. The nature and quality of this interaction and exchange determine the experience of both parties (Bimonte \& Punzo, 2007; Reisinger \& Turner, 2002) and consequently, the guests' willingness to pay and hosts' response and perception of the impact of tourism (Andereck \& Vogt, 2000; Harrill, 2004). Though rarely the case (Sharpley, 2014), research should be in a conceptual framework of host-guest relations in order to identify the phenomenon and explain it better.

This is the aim of the present paper. In an economic perspective, it tries to develop a host-guest interaction model, assuming that feasible development in tourism is an equilibrium path delimited in time and space. It depends on players' preferences (or attitudes) and the interaction between hosts and guests whereby players react to a stimulus and to feedbacks generated by responses. These aspects are emphasized when a relationship between preferences and economic fact exists (Etzioni, 1985). In fact, preferences determine the choice, while evolving due to the experience associated with the economic choice. In such a context, equilibrium is determined endogenously. 


\section{Edgeworth box: a reminder}

In a pure exchange economy there are several consumers. Each is described by her/his preferences and goods endowment and is assumed to behave competitively. Agents are therefore price takers and each is represented by his/her utility function $\left(\mathrm{u}_{\mathrm{i}}\right)$ and initial endowment $\left(\omega_{\mathrm{i}}\right)$. The concept of good is broad: goods may be differentiated in terms of time, location and state of the world. Given their preferences and endowments, agents trade their goods in order to be better off. The main theoretical aspect is thus how goods are allocated among economic agents. In a pure exchange economy with given prices, agents choose the preferred bundle from their consumption set in order to solve the following problem:

$$
\max u_{i}\left(x_{i}\right) \text { such that } p x_{i}=p \omega_{i}
$$

the solution of which is the agent's demand function.

The case of pure exchange contains many of the aspects extant in the larger setting of firms and production (Katz \& Rosen, 1998; Varian, 2010). In economics, a useful tool to analyse the market exchange process and the trading of goods is the Edgeworth Box. It is a convenient way of representing allocations, preferences and endowments in a two-dimensional space and the results are readily generalized to an $\mathrm{n}$-dimensional setting. Essentially, it merges the indifference map between the parties in a trade by inverting the diagram of one agent.

Let $H$ be a hypothetical agent called Hosts, $G$ another agent named Guests and $S$ and $M$ the two traded goods. In general, $H$ 's and $G$ 's exchange bundle is written:

1) $X_{H}=\left(x_{H}^{S}, x_{H}^{M}\right)$ and $X_{G}=\left(x_{G}^{S}, x_{G}^{M}\right)$

and their initial endowment is:

2) $E_{H}=\left(\omega_{H}^{S}, \omega_{H}^{M}\right)$ and $E_{G}=\left(\omega_{G}^{S}, \omega_{G}^{M}\right)$.

A pair of exchange bundles $\left(\mathrm{X}_{\mathrm{H}}\right.$ and $\left.\mathrm{X}_{\mathrm{G}}\right)$ is a feasible allocation if and only if:

3) $x_{H}^{S}+x_{G}^{S}=\omega_{H}^{S}+\omega_{G}^{S}$ where $\omega_{H}^{S}+\omega_{G}^{S}=S$

4) $x_{H}^{M}+x_{G}^{M}=\omega_{H}^{M}+\omega_{G}^{M}$ where $\omega_{H}^{M}+\omega_{G}^{M}=M$

An Edgeworth box can now be drawn to represent the way agents could "exchange" goods in order to achieve a mutually beneficial exchange bundle (figure 1). The box has width $S$ (the total 
endowment of good S) and height M (the total amount of good M). Graphically, we measure H's bundle from the lower left-hand corner of the box, and the G's bundle from the upper right-hand corner. In this way, any feasible allocation between the two agents is represented by a point in the box. The agents' preferences are also represented in the box: H's indifference curves arise from the origin, whereas G's arise from the top right corner. The further the curves are from the H's and G's corner, the higher the agents' utility. All the information needed to represent an exchange economy is effectively represented in graphic form.

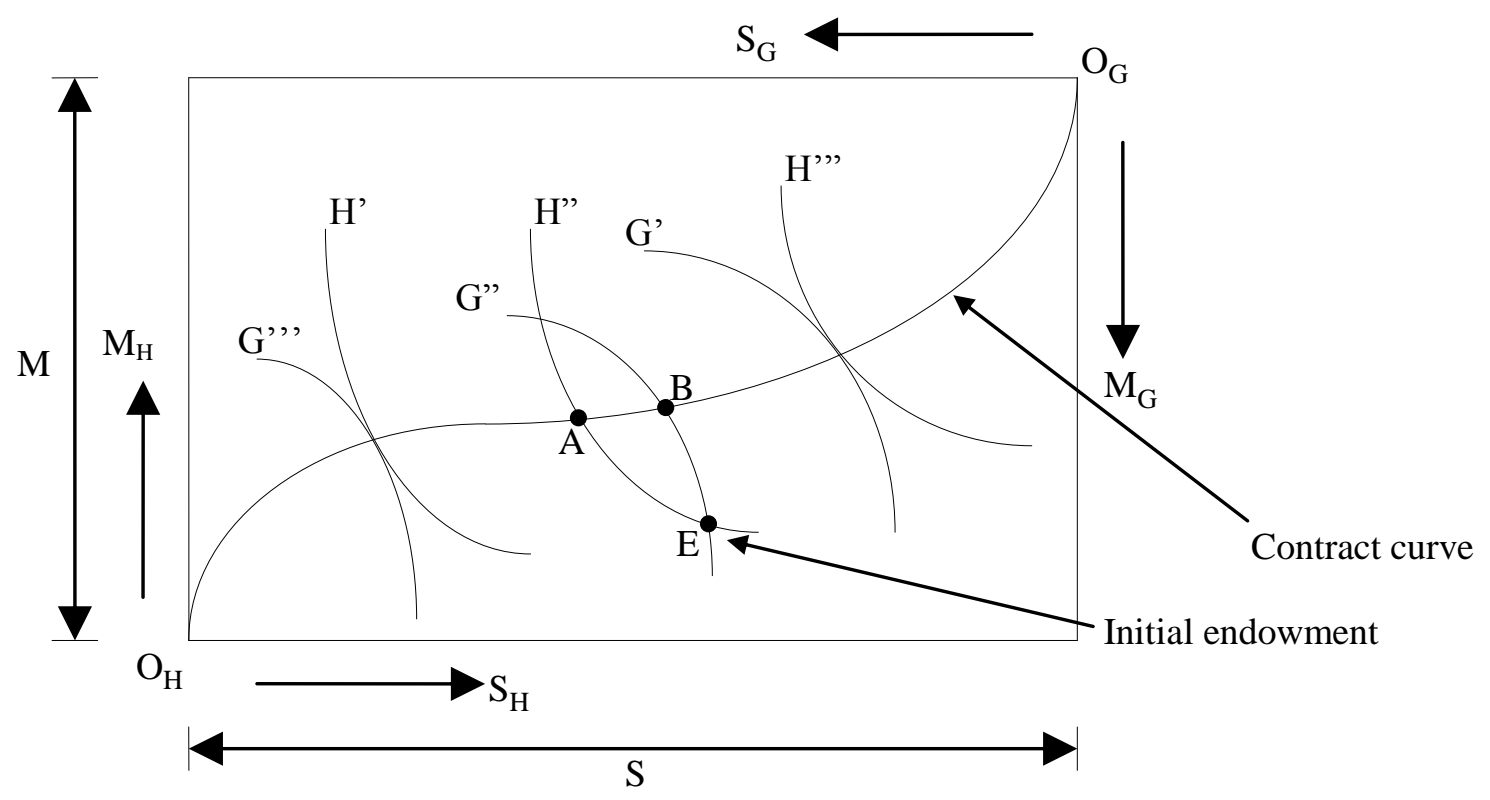

Figure 1: Edgeworth box

As stated above, because of the way the box is constructed, any point in the box represents a feasible allocation between the two agents, but in order to be an equilibrium point, it has to clear the market (demand equals supply) and maximize the agents' utility. From microeconomic theory we know that both these conditions are satisfied when the indifference curves are tangents to each other.

In an Edgeworth box there is an infinite set of these points. This set is called a Pareto Set or the contract curve. This curve stretches from H's origin to that of $\mathrm{G}$ and represents all mutually beneficial outcomes of trade. However, it is worth noting that although the contract curve is independent of initial endowment, the possible relevant outcomes lie on a subset determined by initial endowment. In figure 1, the initial endowment is E and the subset is A-B. In a pure exchange economy, the final outcome (equilibrium) depends on endowment, preferences and market conditions, i.e. prices. We can think of the exchange as a bargaining process in which the agents, given the demand for their endowment, decide competitively on a particular price. The process ends 
once the price clears the market and maximizes the agents' utility. Equilibrium is the point on the contract curve (point $\mathrm{P}$ in figure 2) where the indifference curves are tangents to each other and to budget constraint, whose slope is equal to the price ratio (marginal rate of substitution - MRS) of the two goods. ${ }^{3}$

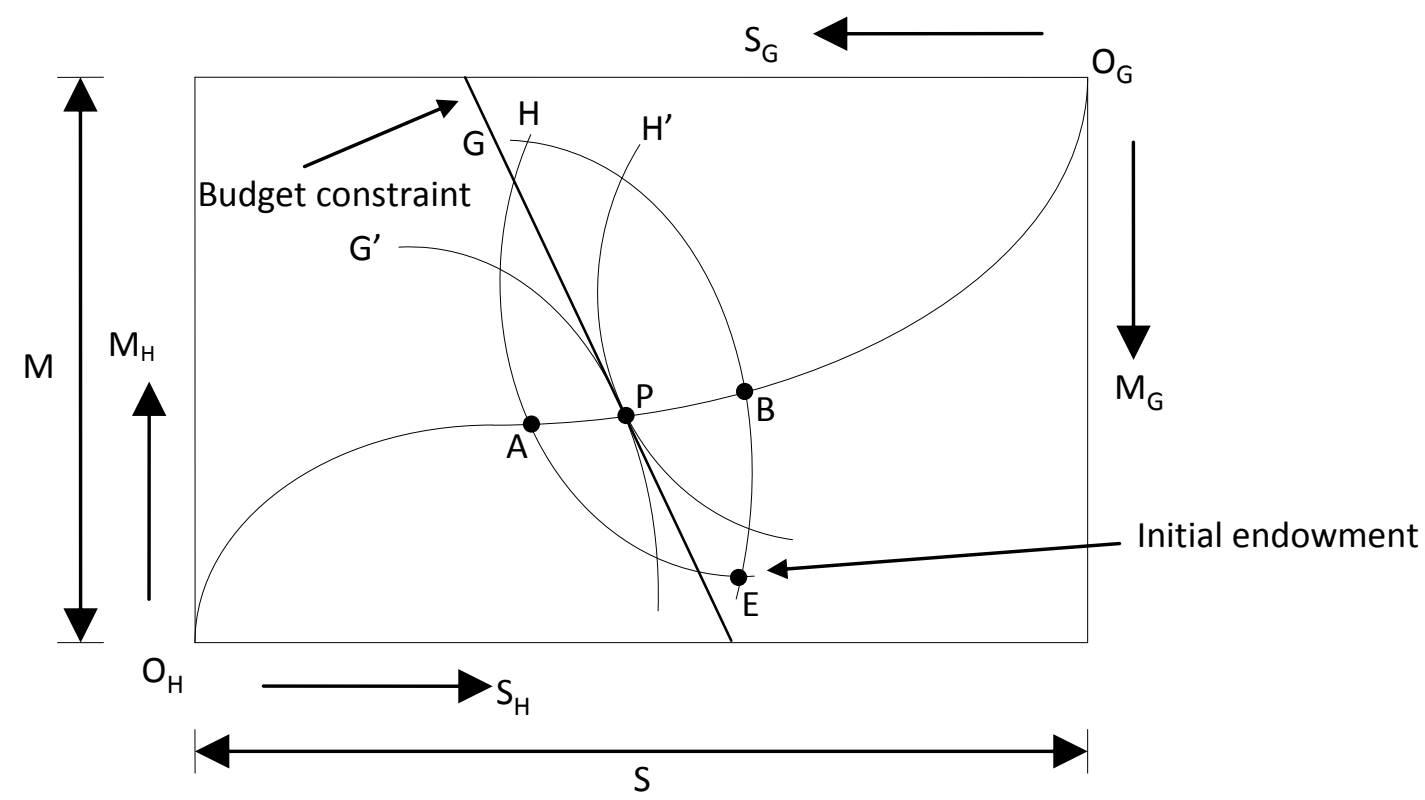

Figure 2: Efficient allocation of goods

\section{A host-guest exchange scheme}

Let us now use the above exchange scheme to build an interpretation framework to deal with tourist development and host-guest interaction. To do so, we first define the two goods involved in the tourist-resident exchange process, i.e. "resource-space" (S) and money (M).

The concept of good considered here is particular and broad. S consists of a set of resources (material and immaterial) that tourists "consume" during their stay. Many are produced by the host communities, which are themselves a locally defined and non-reproducible "tourism product". These resources are economically valuable goods whose conservation can be threatened by the very development of activities that valorise them, tourism being one such activity. Their (rate of) usage may often have critical tapping values, beyond which their use and often economic values dramatically decrease or even disappear altogether. They are mostly common pool resources (CPRs) used by hosts and shared with guests. Their usage may produce competition (generating

\footnotetext{
${ }^{3}$ This is true for what in economics are defined as "pure private goods".
} 
congestion effects) or even conflict (generating externality effects). Competition or even antagonism is of course more acute, the smaller or more fragile is the amount of resources available for tourism. We define the latter "Capacity slack". It is the amount of resources available after take up by hosts (Bimonte \& Punzo, 2007). ${ }^{4}$ It also depends on how similar the two populations are in culture and resource usage.

We assume that capacity slack is mainly managed by the host community, which may decide to open its resource-space to tourism to obtain benefits (mainly additional income, $\mathrm{M}$ ). It trades $\mathrm{S}$ for M, the (max) amount of money that guests are willing to devote to tourism. Roughly speaking, M is payment to use S. In a broad sense, it is the reward for the local community and can be thought of as additional income, social development, cultural interchange, better services.

Since tourist activity is mainly an "experience good", guests and hosts have ex-ante WTAs and WTPs, respectively, and these depend, among other things, on expectations. WTA and WTP evolve over time, because the actual experience depends on and is determined by contextual factors that in our case also depend on the nature and history of host-guest interactions, the variety and likely evolution of which are evident in actual tourism experiences around the world.

Having said this, we can now think of the contract curve as a "tourist development stage" curve. It represents all the possible stages of tourist development. The lower right-hand corner may represent an undiscovered or undeveloped destination. In such situations, $\mathrm{S}$ is totally held/used by $H$ and income by $G$. The subset of possible outcomes is the part of contract curve between A and B, which can be thought of as the relevant capacity slack. Ex-ante (i.e. before trading) its length depends on agents' preferences and resource characteristics. It may even be nil. This is the case of opposition to any level of tourist development. A particular case is also represented by a planned development up to a certain point, e.g. up to social carrying capacity. In these cases tourism (that is $\mathrm{M}$ ) becomes a neutral good for the local community and the latter's indifference curves become vertical. (The opposite is true for a community with no interest in its resource-space.) However, in general, once tourism takes off, the actual length of the contract curve also depends on contextual factors, i.e. the actual experience of interaction and the type of development (equitable vs. unequal). Depending on these factors, it may turn out to be wider or narrower.

How does the exchange process function? Standard neoclassical theory has taught us to think in terms of a continuous and decreasing aggregate demand curve for a private good (decreasing

\footnotetext{
${ }^{4}$ We assume that the amount of resources (which is a bundle) can be measured by a single indicator and be plotted on a single axis. There is no need to complicate the picture in order to illustrate the message.
} 
marginal WTP), obtained as the sum of individual independent demand curves. Because no interaction in consumption arises, then marginal WTP, measured by the market price, is assumed to be equal across consumers. However, the willingness to pay of a tourist and the willingness to accept of a resident generally depend upon the conditions (contextual factors) in which the interaction takes place. Among other things, this means that the individual tourist's demand, as represented by her WTP, is neither uniquely determined nor independent of demand of other individuals. To capture the essence of this aspect, we may focus upon various aspects: the crowding effect, measured by the number of tourists visiting the destination at the same time; community composition effect, measured by the different types of tourists simultaneously visiting that destination; views and values shared with the host community; intensity of resource use. We can expect all these factors to affect the quality of the visiting experience and therefore tourists' WTP and residents' WTA. ${ }^{5}$

In determining the final (temporary and/or unstable) outcome, market and contextual factors intermingle. In general, in line with economic theory, the relative importance of the two goods varies along the relevant curve, so do the MRS between the two goods: the less remains of a good, in relative terms, the higher the assigned value (decreasing marginal utility). Moreover, ceteris paribus, the less resource-space (real or perceived) remaining, the higher the intercommunity conflict; the higher the conflict, the greater hosts' WTA and the lower guests' WTP; the less equitable tourist development is, the stronger host intracommunity and consequently host-guest intercommunity conflicts. To summarize, WTP and WTA depend on what is left of S, qualitatively and quantitatively. This obviously affects MRS (WTA/WTP): when capacity slack is becoming depleted, MRS may become infinite, because of the value of $S$ with respect to that of $M$.

We may therefore have what seems to be an ex-ante efficient outcome on the contract curve, which turns out to be an ex-post inefficient and conflictual outcome outside the contract curve. In fact, actual experience modifies agents' perceptions, changing their indifference curves (figure 3). So what is needed is a private outcome (equilibrium) compatible with social expectations, represented by the WTP to WTA ratio. This may be achieved through policies (e.g. redistributive) that modify the social marginal rate of substitution in terms of income and services, or else policies that reduce the negative impact of tourism on the local community or make the intensity of resource-space use more efficient. This may be particularly useful when populations are internally divided in communities.

\footnotetext{
${ }^{5}$ For more on these aspects, see Bimonte and Punzo (2007).
} 


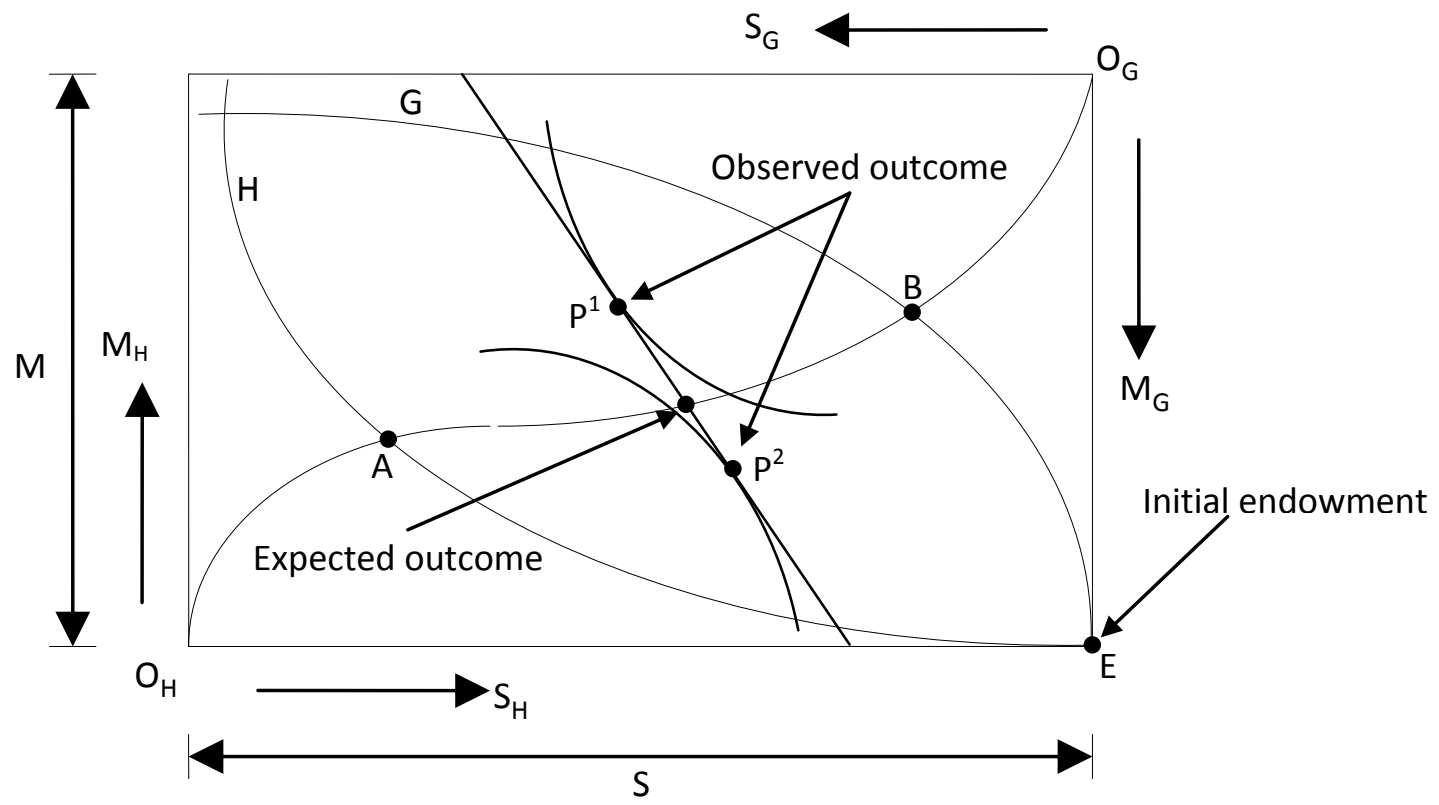

Figure 3: Expected vs. observed outcome

\section{Concluding remarks}

We may now draw some preliminary conclusions. Building on well-established literature, we developed a theoretical economic framework for investigating and hopefully providing some answers to issues revealed by models hitherto used to analyse tourist development at a destination and residents' attitudes to tourism. Unlike previous approaches, it focuses simultaneously on the agents involved as well as the effects of the different development paths and possible interactions between them. It assumes that tourism involves the meeting of at least two not necessarily similar populations, i.e. hosts and guests; that each population, normally divided into communities, has its preferences and expectations with regard to the benefits and costs deriving from tourism; actual benefits and costs may differ because of the nature of the resource-space (the common pool of resources, the use, sharing or exploitation of which has to be agreed upon).

Drawing from social exchange theory, we assume that an exchange takes place between guests and hosts, who try to optimize their well-being while minimizing the costs implied by tourism. According to their preferences, both anticipate and compare prospective costs and benefits. Based on their expectations, hosts define their WTA for endorsing tourist development and guests determine their WTP to engage in tourist activities. An exchange occurs when a balance (equilibrium) between expected costs and benefits emerges for both (all) players. However, depending on contextual factors, the actual outcome may turn out not to be an equilibrium. Non 
equilibrium outcomes cause friction or conflict that may lead to reappraisal of costs and benefits. Equilibrium only emerges when market conditions are compatible with social conditions. This is a policy issue.

The Edgeworth Box is useful for representing this process. Its microeconomic foundation makes it possible to include aspects that previous models were unable to deal with. Ceteris paribus, the theory of decreasing marginal utility of a good (and the increasing marginal disutility associated with the shinking of another good) makes it possible to explain why local communities may change their attitutes to tourism and why tourism may take a certain path (such as that of the Irridex model).

It also confutes the determinism of the TALC model. The dynamics depend on many factors, such as players' preferences and the nature and history of the interactions that affect contextual factors. Moreover, the type of tourist development a destination undertakes may enhance or dampen intraand intercommunity conflicts that in turn affect host WTA and guest WTP. There is nothing deterministic in the tourist-resident interaction or the destiny of a destination.

The interpretative model presented here may be useful to understand and study different situations and to interpret different outcomes. As shown, the scale of the contract curve depends on preferences: the stronger the values and commitment to one's area, the steeper the indifference curve and the smaller the contract space. A less demanding local community has a flatter indifference curve, which implies a larger contract space, all other things being equal. The same applies to tourists.

However, for a given initial endowment and property right on resources, the local community (also in the sense of local government) plays a major role in determining where the final outcome will lie on the contract curve. In fact, it is up to the local community to make the first move, using regulatory and normative instruments (Bimonte, 2008), though this may not always happen (as in the case of a poor community in a developing country). Residents have prime responsibility for the type of tourist that visits their area and the type of tourism that develops. They are also ultimately responsible for the level of manifest or latent conflict caused by development.

\section{References}

Andereck, K., Valentine, K., Knopf, R. \& Vogt, C., 2005. Residents' perceptions of community tourism impacts. Annals of Tourism Research, 32(4), pp. 1056-76. 
Andereck, K. \& Vogt, C., 2000. The relations between resident's attitudes toward tourism and tourism development options. Journal of Travel Research, 39(1), pp. 27-37.

Andriotis, K. \& Vaughan, D., 2003. Urban residents' attitudes toward tourism development: the case of Crete. Journal of Travel Research, 42(2), pp. 172-185.

Ap, J., 1990. Residents' perceptions research on the social impacts of tourism. Annals of Tourism Research, 17(4), pp. 610-616..

Ap, J., 1992. Residents' perceptions on tourism impacts. Annals of Tourism Research, 19(4), pp. 665-690.

Ap, J. \& Crompton, J. L., 1993. Residents' strategies in responding to tourism impacts. Journal of Travel Research, 32(1), pp. 47-50.

Bimonte, S., 2008. The "tragedy of tourism resources" as the outcome of a strategic game A new analytical framework. Ecological Economics, Volume 67, pp. 457-464.

Bimonte, S., \& Faralla, V. (2016). Does residents' perceived life satisfaction vary with tourist season? A two-step survey in a Mediterranean destination, Tourism Management, 55, 199-208.

Bimonte, S. \& Faralla, V., 2015. Happiness and outdoor vacations: Appreciative versus consumptive tourists. Journal of travel Research, 54(2), pp. 179-192.

Bimonte, S. \& Punzo, L., 2007. The evolutionary game between tourist and resident populations and Tourist Carrying Capacity. International Journal of Technology and Globalisation, 3(1), pp. 73-87.

Bimonte, S. \& Punzo, L., 2011. Tourism, residents' attitudes and perceived carrying capacity with an experimental study in five Tuscan destinations. International Journal of Sustainable Development, 14(3/4), pp. 242-261.

Butler, R., 1980. The concept of a tourism area cycle of evolution. Canadian Geographer, 24(1), pp. 5-12.

Butler, R., 2006. The concept of a tourist area life cycle of evolution: Implication for management of resources. In: R. W. Butler, a cura di The tourism area life cycle: Applications and modifications. Clevedon: Channel view publications.

Deery, M., Jago, L. \& Fredline, L., 2012. Rethinking social impacts of tourism research: a new research agenda. Tourism Management, 33(1), pp. 64-73.

Dogan, H., 1989. Forms of adjustment: Sociocultural impacts of tourism. Annals of Tourism Research, 16(2), pp. 216-136.

Doxey, G., 1975. A causation theory of visitor-resident irritants, methodology, and research inferences. Sixth annual conference proceedings of the Travel Research Association. San Diego, CA, Travel and Tourism Research Association, 195-198. 
Dyer, P., Gursoy, D., Sharma, B. \& Carter, J., 2007. Structural modeling of resident perceptions of tourism and associated development on the Sunshine Coast, Australia. Tourism Management, 28(2), pp. 409-422.

Etzioni, A., 1985. Opening the preferences: a socio-economic research agenda. Journal of Behavioral Economics, Volume 14, pp. 183-205.

Fredline, E. \& Faulkner, B., 2000. Host Community Reactions: A Cluster Analysis. Annals of Tourism Research, 27(3), pp. 763-784.

Fridgen, J. D., 1991. Dimensions of tourism. Lansing, MI: The Educational Institute of the American Hotel \& Lodging Association.

Gursoy, D., Chi, C. G. \& Dyer, P., 2010. Locals' attitudes toward mass and alternative tourism: the case of Sunshine Coast, Australia.. Journal of Travel Research, 49(3), pp. 381-394.

Gursoy, D., Jurowski, C. \& Uysal, M., 2002. Resident Attitudes: A Structural Modeling Approach. Annals of Tourism Research, Volume 29, pp. 79-105.

Gursoy, D. \& Kendall, K., 2006. Hosting mega events: Modeling locals' support. Annals of Tourism Research, 33(3), p. 603-623.

Gursoy, D. \& Rutherford, D., 2004. Host attitudes toward tourism. An improved structural model. Annals of Tourism Research, Volume 31, p. 495-516.

Harrill, R., 2004. Residents' attitudes toward tourism development: A literature review with implications for tourism planning. Journal of Planning Literature, 18(1), pp. 1-16.

Jurowski, C. \& Gursoy, D., 2004. Distance effects on residents' attitudes toward tourism. Annals of Tourism Research, 31(2), pp. 296-312.

Jurowski, C., Uysal, M. \& Williams, D., 1997. A theoretical analysis of host community resident reactions to tourism. Journal of Travel Research, 36(2), pp. 3-11.

Katz, M. \& Rosen, H., 1998. Microeconomics. 3rd a cura di New York: McGraw-Hill Companies Inc..

Kayat, K., 2002. Power, social exchanges and tourism in Langkawi: Rethinking resident perceptions. International Journal of Tourism Research, 4(3), pp. 171-191.

Kim, K., Uysal, M. \& Sirgy, M., 2013. How does tourism in a community impact the quality of life of community residents?. Tourism Management, Volume 36, pp. 527-540.

King, B., Pizam, A. \& Milman, A., 1993. Social impacts of tourism. Annals of Tourism Research, Volume 20, p. 650-655.

Lawson, R., Williams, J., Young, T. \& Cossens, J., 1998. A comparison of residents' attitudes towards tourism in 10 New Zealand destinations.. Tourism Management, 19(2), pp. 247-256. 
Mason, P. \& Cheyne, J., 2000. Residents' attitudes to proposed tourism development. Annals of Tourism Research, 27(2), pp. 391-411.

McGehee, N. \& Anderek, K., 2004. Factors predicting rural residents' support for tourism. Journal of Travel Research, 43(2), pp. 131-140..

Monterrubio-Cordero, J. C., 2008. Resident's perception of tourism: A critical theoretical and methodological review. Ciencia Ergo Sum, 15(1), pp. 35-44.

Murphy, P. \& Murphy, A., 2004. Strategic management for tourism communities: Bridging the gaps. Clevedon: Channel View Publications.

Northcote, J. \& Macbeth, J., 2006. Conceptualising yield in sustainable tourism management. Annals of Tourism Research, Volume 33, pp. 199-220.

Nunkoo, R. \& Gursoy, D., 2012. Residents' support for tourism: an identity perspective. Annals of Tourism Research, 39(1), pp. 243-268.

Nunkoo, R., Smith, S. \& Ramkissoon, M., 2013. Resident attitudes to tourism: a longitudinal study of 140 articles from 1984 to 2010. Journal of Sustainable Tourism, 21(1), pp. 5-25.

Nunkoo, R., Smith, S. \& Ramkissoon, M., 2013. Resident attitudes to tourism: a longitudinal study of 140 articles from 1984 to 2010. Journal of Sustainable Tourism, 21(1), pp. 5-25.

Pearce, P., 2009. The Relationship Between Positive Psychology and Tourist Behavior Studies. Tourism Analysis, 14(1), pp. 37-48.

Pearce, P., Filep, S. \& Ross, G., 2011. Tourists, Tourism and the Good Life.. London, New York: Routledge.

Pearce, P., Moscardo, G. \& Ross, G., 1996. Tourism community relationships. Oxford: Elsevier Science Ltd.

Perdue, R., . Long, P. \& Allen, L., 1990. Resident Support for Tourism Development. Annals of Tourism Research, 17(4), pp. 586-599.

Reisinger, Y. \& Turner, L., 2002. Cultural differences between Asian tourist markets and Australian hosts: part 1. Journal of Travel Research, 40(3), pp. 295-315.

Saarinen, J., 2006. Traditions of Sustainability in Tourism Studies. Annals of Tourism Research, Volume 38, pp. 1121-40.

Saarinen, J., Rogerson, C. \& Manwa, H., 2011. Tourism and millennium development goals: Tourism for development?. Current Issues in Tourism, 14(3), p. 201-203.

Sharpley, R., 2008. Tourism, tourists and society. 4th ed. a cura di Huntingdon: Elm Publications.

Sharpley, R., 2014. Host perceptions of tourism: A review of the research. Tourism Management, Volume 42, pp. 37-49. 
Sharpley, R., 2015. Tourism: A vehicle for development . In: R. Sharpley \& D. Telfer, a cura di Tourism and Development: Concepts and Issues. Bristol: Channel View Publications, pp. 3-30.

Telfer, D. \& Sharpley, R., 2008. Tourism and development in the developing world. Abingdon: Routledge.

Teye, V., Sonmez, S. F. \& E., S., 2002. Residents' attitudes towards tourism development. Annals of Tourism Research, Volume 29, pp. 668-88.

Tosun, C., 2002. Host perceptions of impacts: A comparative tourism study. Annals of Tourism Research, 29(1), pp. 231-253.

Vargas-Sánchez, A., Plaza-Mejía, M. \& Porras-Bueno, N., 2009. Understanding residents' attitudes toward the development of industrial tourism in a former mining community. Journal of Travel Research, 47(3), pp. 373-387.

Varian, H., 2010. Intermediate microeconomics. 8th a cura di New York: W.W. Norton and Company.

Wall, G. \& Mathieson, A., 2006. Tourism: Change, impacts and opportunities. Harlow:: Pearson Prentice Hall.

Ward, C. \& Berno, T., 2011. Beyond social exchange theory: Attitudes Toward Tourists. Annals of Tourism Research, 38(4), p. 1556-1569.

Williams, J. \& Lawson, R., 2001. Community issues and resident opinions of tourism. Annals of Tourism Research, 28(2), pp. 269-290.

Woosnam, K., 2012. Using emotional solidarity to explain residents' attitudes about tourism and tourism development. Journal of travel Research, 51(3), pp. 315-327. 